\title{
Comparative assessment of canine-origin Lactobacillus johnsonii CPN23 and dairy-origin Lactobacillus acidophillus NCDC 15 for nutrient digestibility, faecal fermentative metabolites and selected gut health indices in dogs
}

\author{
Sachin Kumar†, Ashok K. Pattanaik* $\neq$, Shalini Sharma, Reema Gupta, Sunil E. Jadhav and Narayan Dutta \\ Niche Area of Excellence in Clinical Nutrition, Division of Animal Nutrition, ICAR Indian Veterinary Research Institute, Izatnagar-243 122, \\ India
}

(Received 14 November 2016 - Final revision received 29 May 2017 - Accepted 16 June 2017)

Journal of Nutritional Science (2017), vol. 6, e38, page 1 of 5

doi:10.1017/jns.2017.35

Abstract

The present experiment was undertaken to validate a probiotic of canine origin for its potential use in dogs. A total of fifteen adult female Labrador dogs were allocated to three equal groups and fed a basal diet without probiotic (control) or with probiotic of either canine (Lactobacillus jobnsonii CPN23; cPRO) or dairy (L. acidophilus NCDC 15; dPRO) origin for 9 weeks. The digestibility of most macronutrients remained similar among the groups; however, fibre digestibility was improved $(P=0.034)$ in dogs receiving cPRO. The faecal fermentative metabolites ammonia $(P<0.05)$ and lactate $(P=0.094)$ were altered favourably, indicating a positive influence of both probiotics. Faecal concentrations of acetate, propionate and butyrate were increased $(P<0 \cdot 01)$ in both probiotic groups. However, improvements were higher in cPRO $v$. dPRO. The delayed-type hypersensitivity reaction to intradermal inoculation of phytohaemagglutinin-P was higher $(P=0.053)$ in $\mathrm{cPRO}$ as compared with control. The antibody response to sheep erythrocytes was, however, similar across the three groups. Overall, in dogs, the canine-origin probiotic was superior when compared with the dairy-origin probiotic.

Key words: Canine nutrition: Faecal metabolites: Lactobacillus: Species-specific probiotics

Probiotics are micro-organisms that are added to the diet to exert beneficial effects on the host. One important criterion for selection of a probiotic is the host species specificity ${ }^{(1)}$. It is believed that probiotic organisms should be naturally occurring in the target species to be effective ${ }^{(2)}$ by inducing a greater production of SCFA in the hindgut and effecting optimal mucosal immunity. SCFA, in turn, play important health-promoting roles in the maintenance of gut barrier function by contributing to energy needs of host cells, absorption of select nutrients and inhibition of pathogenic micro-organisms ${ }^{(3)}$. Probiotics have the potential to stimulate innate immune responses without inducing inflammation; they interact with dendritic cells and follicle-associated epithelial cells and initiate responses mediated by macrophages and T- and B-lymphocytes ${ }^{(4)}$.

Adhesion of probiotic bacteria to epithelial cells is host specific; hence, for improved colonisation, the probiotic bacteria should originate from the same host species ${ }^{(5)}$. Commensal organisms may exert species-specific effects, and therefore, a successful canine probiotic organism would ideally be derived from the canine gastrointestinal tract ${ }^{(6)}$. However, there are

Abbreviations: BCFA, branched-chain fatty acid; CMI, cell-mediated immunity; cPRO, probiotic of canine origin (Lactobacillus jobnsonii CPN23); dPRO, probiotic of dairy origin (Lactobacillus acidophilus NCDC 15); DTH, delayed-type hypersensitivity.

* Corresponding author: Dr A. K. Pattanaik, fax +1 217333 2289, email ashokkp@illinois.edu/akpattanaik1@gmail.com

† Present address: Dairy Cattle Nutrition Division, ICAR-National Dairy Research Institute, Karnal-132 001, India.

$\ddagger$ Present address: Department of Food Science and Human Nutrition, Carl R. Woese Institute for Genomic Biology, University of Illinois at Urbana-Champaign, Urbana, IL 61801, USA. 
only a few studies on canine-sourced bacteria as probiotics for $\operatorname{dogs}{ }^{(7,8)}$.

Further, the available literature shows that most of the probiotics studies in dogs have been carried out with extruded pet foods as the basal diet. In most developing countries, including India, pet dogs are reared mainly on home-cooked diets of varied composition. However, few studies have examined the effects of probiotics when supplemented with homemade vegetarian diets. The present study, therefore, evaluated the potential of a canine-origin probiotic $v$. a dairy-origin probiotic for its possible use in dogs fed a homemade vegetarian diet.

\section{Materials and methods}

\section{Animals, housing and management}

The study protocol was approved by the Institutional Animal Ethics Committee, and was carried out in conformity with Committee for the Purpose of Control and Supervision of Experiments on Animals (CPCSEA) guidelines. Dogs used for the study were housed under hygienic conditions in a well-ventilated kennel having separate cubicles $(1.52 \times 0.91$

$\mathrm{m}^{2}$ ) for individual housing and care. The dogs were let out in an open space adjacent to the kennel in the morning and evening for exercise and socialisation except during the collection period.

\section{Animals and diets}

Fifteen adult female Labrador dogs (aged about 5 years; 22.9 (SE $0 \cdot 6) \mathrm{kg}$ average body weight) were randomly allocated to three equal groups based on body weight and fed a pressurecooked moist diet. The dogs had an ideal body condition score and were declared healthy by a veterinarian based on medical history, physical examination, complete blood count and serum biochemistry. The basal diet was specially formulated to meet National Research Council recommendations (adequate intake) for adult maintenance ${ }^{(9)}$ (Supplementary Table S1). The amount of food was calculated to meet the maintenance energy requirement $(\mathrm{kcal}=130 \times \mathrm{kg}$ body weight $^{0.75} ; \mathrm{kJ}=544 \times \mathrm{kg}$ body weight $\left.{ }^{0.75}\right)^{(9)}$. The diet was supplemented with either no probiotics (control), or with a probiotic of canine origin (Lactobacillus jobnsonii CPN23; cPRO) or dairy origin (Lactobacillus acidophilus NCDC 15; dPRO). The control group received a placebo (De Man, Rogosa and Sharpe broth), while cPRO and dPRO groups received cultures of the respective probiotics (at $2 \cdot 3 \times 10^{8}$ colony-forming units/animal per d) mixed with the basal diet.

The canine-origin probiotic L. johnsonii CPN23 was previously developed in our laboratory and characterised using 16S rRNA analyses (GenBank accession no. KP065494). A freeze-dried pure culture of the L. acidophilus NCDC 15 strain, procured from the National Collection of Dairy Culture (NCDC), National Dairy Research Institute (Karnal, India) was used for feeding the dPRO group.

All the dogs had $24 \mathrm{~h}$ access to clean and fresh water ad libitum. Before the study, dogs were adapted to the basal diet for a period of $15 \mathrm{~d}$. Each individual dog's ration was divided into two equal portions and fed once each in the morning (09.00 hours) and evening (17.00 hours). Probiotics were administered only in the morning. The experimental period lasted for 9 weeks.

\section{Experimental protocol}

Food consumption was monitoring daily. A $4 \mathrm{~d}$ digestibility trial was conducted after 7 weeks of feeding as described earlier $^{(10)}$ to calculate the apparent digestibility (nutrient intake - nutrient output/nutrient intake $\times 100$ ). A 1-4-point palatability score was adopted for subjective assessment of the acceptability of the experimental diets ${ }^{(11)}$. The faeces voided by individual dogs, collected quantitatively over the preceding $24 \mathrm{~h}$, were weighed individually for each dog, mixed thoroughly and used for further sampling and analysis. The faecal consistency score was recorded based on a 15 -point scale ${ }^{(11)}$. Three different aliquots were drawn from the faecal samples and processed for the determination of DM, $\mathrm{N}$ and fermentative metabolites as described elsewhere $^{(10)}$. The samples of faeces and food were dried at $60^{\circ}$ $\mathrm{C}$ in a forced-draft oven, ground through a $2 \mathrm{~mm}$ screen in a laboratory mill (SM100; Retsch $\mathrm{GmbH}$ ) and stored in airtight high-density polyethylene jars pending further analysis.

\section{Laboratory analyses}

The ground samples of food and faeces were analysed for DM, organic matter, crude protein, ether extract, crude fibre and crude ash, while N-free extract was calculated ${ }^{(12)}$. The $\mathrm{pH}$ of the faecal samples was determined by a $\mathrm{pH}$ meter (Eutech Instruments). Lactate, ammonia, SCFA and branchedchain fatty acid (BCFA) concentrations in the faecal samples were analysed as described earlier ${ }^{(13)}$.

Cell-mediated immunity (CMI) was assessed at 8 weeks by measurement of skin indurations as type-IV delayed-type hypersensitivity (DTH) reaction to phytohaemagglutinin-P (Sigma) as a mitogen, as detailed previously ${ }^{(14)}$. For the humoral immune response, dogs were intravenously injected with $1 \mathrm{ml}$ of a $10 \%$ suspension of washed sheep erythrocytes after 5 weeks of experimental feeding. Serum samples collected at periodic intervals $(0,7,14,21$ and $28 \mathrm{~d})$ were used for an antibody titre assay using the microtitre haemagglutination procedure ${ }^{(15)}$.

\section{Statistics}

The data were analysed by one-way ANOVA using SPSS 20.0 (SPSS Inc.). Means were compared using Tukey's post hoc test. Additionally, contrast analysis was employed to ascertain the differences, if any, between the treatments cPRO and dPRO. Significance was declared at $P \leq 0.05$.

\section{Results and discussion}

\section{Nutrient intake and digestibility}

Data on food intake and apparent digestibility are presented in Table 1 . The palatability of the diet and daily food intake were 
Table 1. Effect of source of probiotics on the food intake and digestibility of nutrients in Labrador dogs (Mean values with their standard errors; $n 5$ )

\begin{tabular}{|c|c|c|c|c|c|c|c|}
\hline & \multicolumn{6}{|c|}{ Dietary group } & \multirow[b]{3}{*}{$P^{*}$} \\
\hline & \multicolumn{2}{|c|}{ Control } & \multicolumn{2}{|c|}{ cPRO } & \multicolumn{2}{|c|}{ dPRO } & \\
\hline & Mean & SE & Mean & $\mathrm{SE}$ & Mean & SE & \\
\hline Palatability $\dagger$ & 1.72 & 0.31 & 1.68 & 0.28 & 1.68 & 0.16 & 0.961 \\
\hline \multicolumn{8}{|l|}{ Mean daily food (DM) intake } \\
\hline DM intake (g) & 354.4 & $22 \cdot 9$ & $361 \cdot 8$ & $50 \cdot 2$ & 364.9 & $20 \cdot 1$ & 0.883 \\
\hline DM intake $\left(\mathrm{g} / \mathrm{kg}\right.$ body weight $\left.{ }^{0.75}\right)$ & 34.45 & 0.05 & 34.50 & 0.26 & 34.44 & 0.12 & 0.886 \\
\hline \multicolumn{8}{|l|}{ Digestibility of nutrients $(\mathrm{g} / \mathrm{kg})$} \\
\hline DM & 830 & 23.7 & 836 & 40.5 & 847 & 11.0 & 0.622 \\
\hline Organic matter & 848 & $21 \cdot 3$ & 853 & $37 \cdot 1$ & 865 & 11.5 & 0.595 \\
\hline Crude protein & 796 & $30 \cdot 3$ & 816 & 35.7 & 826 & 24.5 & 0.317 \\
\hline Ether extract & 877 & 7.5 & 873 & $10 \cdot 4$ & 890 & 5.5 & 0.341 \\
\hline Crude fibre & $354^{\mathrm{a}}$ & $15 \cdot 4$ & $419^{b}$ & 13.7 & $386^{a, b}$ & $16 \cdot 4$ & 0.034 \\
\hline $\mathrm{N}$-free extract & 904 & $9 \cdot 0$ & 901 & $17 \cdot 7$ & 914 & $6 \cdot 6$ & 0.720 \\
\hline
\end{tabular}

Control, basal diet alone; cPRO, basal diet supplemented with probiotic of canine origin; dPRO, basal diet supplemented with probiotic of dairy origin.

${ }_{\mathrm{a}, \mathrm{b}}$ Mean values with unlike superscript letters were significantly different $(P \leq 0.05)$.

* Based on one-way ANOVA.

† Based on a 1-4-point scale.

similar among the groups. The apparent digestibility of DM, crude protein, ether extract and N-free extract was not influenced by the source of probiotics. However, the observed increase $(P=0.034)$ in crude fibre digestibility in the cPRO group could have been due to greater fermentability of the undigested fibre entering the hindgut, possibly due to an elevated population of fibrolytic microbes induced by the canine-origin probiotic L. johnsonii CPN23.

\section{Faecal characteristics}

Data on faecal characteristics are presented in Table 2. There was no influence of the probiotics on the faecal score or on the frequency of defecation. A significant $(P=0.012)$ reduction in faecal ammonia concentration was evident in both the cPRO and dPRO groups in comparison with the control. Ammonia is formed during colonic fermentation of protein and is considered detrimental to health. Probiotics are presumed to induce lowered production of ammonia. Faecal lactate tended to be higher $(P=0.091)$ in the cPRO group as compared with control. Additionally, contrast analysis also revealed a trend for higher $(P=0.059)$ lactate in the cPRO group compared with the dPRO group. Increased lactate production along with SCFA lowers the $\mathrm{pH}$ of the hindgut which, besides facilitating greater protonation of ammonia, leading in turn to its higher faecal excretion ${ }^{(16)}$, is considered detrimental to pathogenic micro-organisms ${ }^{(17)}$.

Faecal concentrations of both acetate and butyrate were higher $(P<0 \cdot 001)$ in the cPRO group than the $\mathrm{dPRO}$ group which, in turn, were higher as compared with control. Additionally, contrast analysis also revealed higher acetate $(P=0.019)$ and butyrate $(P=0.001)$ levels in the cPRO group than the dPRO group, indicative of better adaptation of the canine-origin probiotic in the hindgut of the dogs in comparison with the dairy-origin probiotic. Acceleration in the net production of SCFA and lactic acid by supplementation of probiotics lowers the net production of ammonia, and a similar result was evident in the present study. Faecal levels of isovalerate were lower $(P=0.037)$ in the dPRO group while those of valerate were lower $(P<0.05)$ in the cPRO group compared with control. Consequently, faecal levels of total BCFA were reduced $(P<0 \cdot 01)$ in the cPRO group in comparison with control. The BCFA isobutyrate and isovalerate are produced from protein fermentation, specifically from the deamination of valine and leucine, respectively, and are generally believed to be putrefactive leading to production of toxic metabolites deleterious for host health $^{(18,19)}$. The present observation of a generalised reduction in BCFA in both the probiotic-supplemented groups, therefore, is indicative of their health-promoting effects. Further, the reduction $(P<0.05)$ in the total BCFA in the cPRO group $v$. control is suggestive of the advantages of using the species-specific probiotic in dogs.

\section{Immune response}

Skin induration tended to improve $(P=0.053)$ in the cPRO group $(8 \cdot 3(\mathrm{sE} 0.3) \mathrm{mm}$ ) group when compared with control $(7.5(\mathrm{SE} 0.2) \mathrm{mm}$ ) while that of the dPRO group (7.9) (SE $0 \cdot 3) \mathrm{mm}$ ) was comparable with both. There was, however, no variation in the antibody response against sheep erythrocytes among the three dietary groups. The CMI response, mediated by thymus-derived T-lymphocytes which are responsible for DTH reactions, is considered as a good indicator of the effector phase of the CMI response in vivo ${ }^{(20)}$. The improvements evident in the DTH response by the cPRO group $\operatorname{dog} v$. the control, in turn, imply that the canine-origin probiotic acted better at inducing an augmented CMI response than that of the dairy-origin probiotic. Stimulation of systemic components of the immune system, in particular the CMI, may help to regulate changes in the gut microflora, for example by increasing macrophage phagocytic activity using lactic acid bacteria $^{(21)}$. Similarly, use of Jerusalem artichoke as a prebiotic has been reported to improve the DTH response to phytohaemagglutinin-P in $\operatorname{dogs}{ }^{(22)}$. 
Table 2. Effect of source of probiotic on the physical and fermentative indices of faeces of Labrador dogs (Mean values with their standard errors; $n$ )

\begin{tabular}{|c|c|c|c|c|c|c|c|}
\hline \multirow[b]{3}{*}{ Attributes } & \multicolumn{6}{|c|}{ Dietary group } & \multirow[b]{3}{*}{$P+$} \\
\hline & \multicolumn{2}{|c|}{ Control } & \multicolumn{2}{|c|}{ cPRO } & \multicolumn{2}{|c|}{ dPRO } & \\
\hline & Mean & $\mathrm{SE}$ & Mean & $\mathrm{SE}$ & Mean & $\mathrm{SE}$ & \\
\hline \multicolumn{8}{|l|}{ Physical characteristics } \\
\hline Faecal score $\ddagger$ & 2.53 & 0.06 & $2 \cdot 76$ & 0.54 & $2 \cdot 67$ & 0.15 & 0.553 \\
\hline Defecation frequency (times/d) & 1.85 & 0.38 & 1.75 & 0.35 & 1.95 & 0.33 & 0.679 \\
\hline \multicolumn{8}{|l|}{ Faeces voided $(\mathrm{g} / \mathrm{d})$} \\
\hline Fresh (as is) & $225 \cdot 15$ & 52.54 & $221 \cdot 89$ & $42 \cdot 87$ & 211.89 & 46.07 & 0.900 \\
\hline Dry & $60 \cdot 24$ & 9.61 & $58 \cdot 24$ & 11.60 & 55.63 & 4.15 & 0.727 \\
\hline \multicolumn{8}{|l|}{ Faecal composition ( $\mathrm{g} / \mathrm{kg}$ ) } \\
\hline DM & $217 \cdot 2$ & 36.5 & 208.5 & $10 \cdot 7$ & 213.2 & 29.7 & 0.888 \\
\hline Moisture & $782 \cdot 8$ & 36.5 & 791.5 & $10 \cdot 7$ & $786 \cdot 8$ & 29.7 & 0.888 \\
\hline \multicolumn{8}{|l|}{ Faeces (g/kg DM consumed) } \\
\hline Wet faeces & 639.5 & $161 \cdot 8$ & $624 \cdot 7$ & $145 \cdot 3$ & $579 \cdot 1$ & $109 \cdot 9$ & 0.783 \\
\hline Dry faeces & $169 \cdot 8$ & $23 \cdot 7$ & $164 \cdot 1$ & 40.5 & $152 \cdot 6$ & $11 \cdot 0$ & 0.622 \\
\hline \multicolumn{8}{|l|}{ Chemical characteristics } \\
\hline $\mathrm{pH}$ & $6 \cdot 26$ & 0.44 & 6.02 & 0.19 & $6 \cdot 16$ & 0.25 & 0.480 \\
\hline Ammonia ( $\mu \mathrm{mol} / \mathrm{g} \mathrm{DM})$ & $32 \cdot 63^{\mathrm{b}}$ & 3.23 & $26 \cdot 45^{\mathrm{a}}$ & $3 \cdot 18$ & $27 \cdot 20^{\mathrm{a}}$ & $2 \cdot 36$ & 0.012 \\
\hline Lactate $(\mu \mathrm{mol} / \mathrm{g} \mathrm{DM})$ & $16 \cdot 93$ & 3.48 & $22 \cdot 13$ & 2.50 & 19.98 & $4 \cdot 11$ & 0.094 \\
\hline \multicolumn{8}{|l|}{ SCFA $(\mu \mathrm{mol} / \mathrm{g} \mathrm{DM})$} \\
\hline Acetate & $354.70^{\mathrm{a}}$ & 41.56 & $490 \cdot 41^{c}$ & $46 \cdot 72$ & $428.94^{b}$ & $36 \cdot 34$ & $0.001^{*}$ \\
\hline Propionate & $199 \cdot 21^{\mathrm{a}}$ & 32.78 & $213.51^{a, b}$ & $20 \cdot 07$ & $244.69^{b}$ & 34.53 & 0.086 \\
\hline Butyrate & $73.39^{a}$ & $10 \cdot 14$ & $116 \cdot 33^{\mathrm{C}}$ & 13.59 & $88.20^{b}$ & $7 \cdot 11$ & $<0.0001^{*}$ \\
\hline Total SCFA & $627 \cdot 31^{a}$ & 81.22 & $820 \cdot 26^{b}$ & 67.82 & $761 \cdot 82^{b}$ & 49.83 & 0.002 \\
\hline \multicolumn{8}{|l|}{$\mathrm{BCFA}(\mu \mathrm{mol} / \mathrm{g} \mathrm{DM})$} \\
\hline Isobutyrate & 4.75 & 1.33 & 4.25 & 1.01 & 3.85 & 0.80 & 0.435 \\
\hline Isovalerate & $4 \cdot 23^{\mathrm{b}}$ & 0.37 & $3.83^{a, b}$ & 0.42 & $3.09^{\mathrm{a}}$ & 0.91 & 0.037 \\
\hline Valerate & $14.98^{\mathrm{b}}$ & 3.40 & $9.57^{\mathrm{a}}$ & 1.61 & $13 \cdot 21^{a, b}$ & 3.86 & $0.049^{\star}$ \\
\hline Total BCFA & $23.96^{\mathrm{b}}$ & 3.21 & $17 \cdot 65^{\mathrm{a}}$ & 2.47 & $20 \cdot 15^{a, b}$ & 3.72 & 0.026 \\
\hline
\end{tabular}

Control, basal diet alone; cPRO, basal diet supplemented with probiotic of canine origin; dPRO, basal diet supplemented with probiotic of dairy origin; BCFA, branched-chain fatty acids.

a,b,c Mean values with unlike superscript letters were significantly different $(P \leq 0.05)$.

* Significant differences between cPRO and dPRO by contrast analysis.

† Based on one-way ANOVA.

$\ddagger$ Based on a 1-5-point scale.

\section{Conclusion}

The results are indicative of the superiority of a canine-origin probiotic over a dairy-origin probiotic, when supplemented in the diet of dogs.

\section{Supplementary material}

The supplementary material for this article can be found at https://doi.org/10.1017/jns.2017.35

\section{Acknowledgements}

The first author (S. K.) acknowledges the financial assistance provided by the Indian Veterinary Research Institute, Izatnagar in the form of a Senior Research Fellowship. This work was supported by the Indian Council of Agricultural Research, New Delhi under the Niche Area of Excellence programme.

S. K., A. K. P., S. E. J. and N. D. contributed to the experimental design; S. K. and S. S. performed the animal experiment; S. K., R. G. and S. S. performed the laboratory analyses; S. K. and A. K. P. performed the statistical analyses; S. K., N. D. and S. E. J. wrote the manuscript; A. K. P. critically reviewed the manuscript.

There were no conflicts of interest.

\section{References}

1. Ouwehand AC, Salminen S \& Isolauri E (2002) Probiotics: an overview of beneficial effects. Anton van Leeuwen 82, 279-289.

2. Kailasapathy K \& Chin J (2000) Survival and therapeutic potential of probiotic organisms with reference to Lactobacillus acidophilus and Bifidobacterium spp. Immunol Cell Biol 78, 80-88.

3. Rios-Covian D, Ruas-Madiedo P, Margolles A, et al. (2016) Intestinal short chain fatty acids and their link with diet and human health. Front Microbiol 7, 185.

4. Vanderpool C, Yan F \& Brent Polk D (2008) Mechanism of probiotic action: implications for therapeutic application in inflammatory bowel diseases. Inflamm Bowel Dis 14, 1585-1596.

5. Fuller R (1986) Probiotics. Soc Appl Bacteriol Symp Ser 15, 1S-7S.

6. McCoy S \& Gilliland SE (2007) Isolation and characterization of Lactobacillus species having potential for use as probiotic cultures for dogs. J Food Sci 72, M94-M97.

7. Beasley S, Manninen TJK \& Saris PEJ (2006) Lactic acid bacteria isolated from canine faeces. J Appl Microbiol 101, 131-138.

8. Manninen TJK, Rinkinen ML, Beasley SS, et al. (2006) Alteration of the canine small-intestinal lactic acid bacterium microbiota by feeding of potential probiotics. Appl Environ Microbiol 72, 6539-6543.

9. National Research Council (2006) Nutrient Requirements of Dogs and Cats. Washington, DC: National Academies Press.

10. Kore KB, Pattanaik AK, Das A, et al. (2009) Evaluation of alternative cereal sources in dog diets: effect on nutrient utilisation and hindgut fermentation characteristics. J Sci Food Agric 89, 2174-2180

11. Strickling JA, Harmon DL, Dawson KA, et al. (2000) Evaluation of oligosaccharide addition to dog diets: influences on nutrient 
digestion and microbial population. Anim Feed Sci Technol 86, 205219.

12. Association of Official Analytical Chemists (1995) Official Methods of Analysis, 16th ed. Washington, DC: AOAC International.

13. Samal L, Chaturvedi VB, Saikumar G, et al. (2015) Prebiotic potential of Jerusalem artichoke (Helianthus tuberosus L.) in Wistar rats: effects of levels of supplementation on hindgut fermentation, intestinal morphology, blood metabolites and immune response. $J S_{c i}$ Food Agric 95, 1689-1696.

14. Pattanaik AK, Khan SA \& Goswami TK (2007) Influence of iodine on nutritional, metabolic and immunological response of goats fed Leucaena leucocephala leaf meal diet. J Agric Sci 145, 395-405.

15. Wegmann TG \& Smithies O (1966) A simple hemagglutination system requiring small amounts of red cells and antibodies. Transfusion 6, 67-73.

16. Cummings JH, Hill MJ, Jenkins DJ, et al. (1976) Changes in faecal composition and colonic function due to cereal fiber. Am J Clin Nutr 29, 1468-1473.
17. Barrow PA (1992) Probiotics for chickens. In Probiotics: The Scientific Basis, pp. 255-257 [R Fuller, editor]. London: Chapman and Hall.

18. Benyacoub J, Maulden GLC, Cavadini C, et al. (2003) Supplementation of food with Enterococcus faecium (SF68) stimulates immune functions in young dogs. J Nutr 133, 1158-1162.

19. Rehman A, Heinsen FA, Koenen ME, et al. (2012) Effects of probiotics and antibiotics on the intestinal homeostasis in a computer controlled model of the large intestine. BMC Microbiol 12, 47.

20. Kim HW, Chew BP, Wong TS, et al. (2000) Dietary lutein stimulates immune response in the canine. Vet Immunol Immunopathol 74, 315-327.

21. Hatcher GE \& Lambrecht RS (1993) Augmentation of macrophage phagocytic activity by cell-free extracts of selected lactic acidproducing bacteria. J Dairy Sci 76, 2485-2492.

22. Samal L, Chaturvedi VB, Baliyan S, et al. (2012) Jerusalem artichoke as a potential prebiotic: influence on nutrient utilization, hindgut fermentation and immune response of Labrador dogs. Anim Nutr Feed Technol 12, 343-352. 